\title{
Duration matters: peer effects on academic achievement with random assignment in the Chinese context
}

\author{
Cheng Cheng(D)
}

\author{
Correspondence: chengcheng@xjtu. \\ edu.cn \\ Department of Sociology, School of \\ Humanities and Social Sciences, \\ Xi'an Jiaotong University, 28 \\ Xianning West Road, Xi'an 710049, \\ Shaanxi Province, People's Republic \\ of China
}

\begin{abstract}
This paper goes beyond the most popular perspective of family social capital among existing research and examines the effect of peer social capital on adolescent academic achievement. Using the official data from a Chinese university and taking into account the endogeneity problems, this paper finds that peer academic performance has a significant effect on human capital accumulation among university students. We have different findings, however, from research abroad. First, peer social capital has an indirect rather than a direct effect. Second, the influence of initial randomly assigned peers tends to increase over time. However, this increase of influence is only present among peers from similar social class backgrounds. Among peers from different backgrounds, the influence remains almost unchanged. In addition to this, the influence of peer social capital is not significantly different among students from different social class backgrounds.
\end{abstract}

Keywords: Peer social capital, Academic achievement, The mechanism of peer effects, Natural experiment, Social class background

The man who associates chiefly with the wise and the virtuous, though he may not himself become either wise or virtuous, cannot help conceiving a certain respect at least for wisdom and virtue; and the man who associates chiefly with the profligate and the dissolute, though he may not himself become profligate and dissolute, must soon lose, at least, all his original abhorrence of profligacy and dissolution of manners.

--- Adam Smith The Theory of Moral Sentiments

\section{Introduction}

Achieved factors centered around human capital are the decisive elements of class mobility in modern society (Blau and Duncan 1967; Brand and Yu 2010), as well as crucial strategic aspects of national renaissance and development (Schultz 1961; Becker 1962). How to more efficiently train students of human capitals like professional skills, creative spirits, and practical capability is an important and real topic for researchers. Taking the social network that actors are embedded in as the analytical perspective, this paper discusses the mechanism of influence and causal effect of peer social capital

(c) The Author(s). 2020 Open Access This article is distributed under the terms of the Creative Commons Attribution 4.0 International License (http://creativecommons.org/licenses/by/4.0/), which permits unrestricted use, distribution, and reproduction in any medium, provided you give appropriate credit to the original author(s) and the source, provide a link to the Creative Commons license, and indicate if changes were made. 
in training and improvement of human capital, as well as the trend of change and class difference of this influence.

James Coleman's research has focused on the positive development of teenagers, especially their academic achievement. Systematically reviewing decades' worth of research, Coleman summarizes the social capital effect in the process by which human capital is created in the case of the US. He sees both social capital within the family (such as family structure and parent-child relation) and social capital outside of the family (the connection between parents and schools, among parents, and among students) as crucial factors that influence academic achievement (Coleman 1988). Zhao and Hong (2012) juxtapose Coleman's social closure perspective and Bourdieu's network resource perspective in the case of China and find that both have an effect on the training of students' human capital. Despite studies that cast doubts on the importance of "generational closure" (Morgan and Sorensen 1999), the Chinese academia has reached a consensus about the influence that parental social network and family social capital have on children's academic achievement. The flies in the ointment are (a) that social ties among students and their consequences have not received the attention they deserve; (b) that most of the research focuses on middle schoolers and primary schoolers, but overlook the academic achievement of college students, who are free from the supervision and constraint of parents and enjoy more autonomous space; and (c) that the identification of causal effects is inaccurate and unconvincing.

Departs from these possibilities for further development, this paper tries to examine the causal effect of peer social capital on the academic achievement of college students and the variation trend of the effect. In fact, countless research have discovered the crucial effect (Haynie and Osgood 2005; Hasan and Bagde 2013; Guo et al. 2015) and even decisive impact (Coleman 1961; Rich 2009) that peer network (such as friends, classmates, and roommates) have on the development of teenagers (such as academic performance, dropouts, physical and mental health, and deviant behavior). But the discussion on peer influence is often confronted with extreme methodological difficulties. To test whether peer network effect truly exists, we need to overcome at least three technical challenges: selection bias, common environmental factors, and the reflection problem. ${ }^{1}$

Sacerdote (2001) and Zimmerman (2003) have proposed an adequate analytical strategy for identifying the causal effect of peer networks-a "natural experiment" of randomly assigned roommates. This method collects data from only one school and therefore does not have the representativeness that sampling surveys afford, but it can provide a clean and convincing causal effect. For this advantage, the method provides important support to studies of peer network and positive teenager development and have produced a number of high-quality follow-up studies (for a review, see Sacerdote 2011). However, these researches focus on identifying causal effects and rarely talks about internal mechanisms by with peer network influences academic achievement (Stinebrickner and Stinebrickner 2006; Sacerdote 2011; Hasan and Bagde 2013).

Chinese universities have a different modus operandi from European and American universities when it comes to dorm assignment. For example, most European and

${ }^{1}$ For more on these challenges and how they are dealt with in this paper, see the research strategy" section of this paper. 
American colleges only require their incoming freshmen to live on campus, but in most Chinese colleges (including University $C$ discussed in this paper), students are required to live in school dorms all through their undergraduate time. ${ }^{2}$ This situation has created a precious opportunity for us to capture the long-term effect of peer social capital. ${ }^{3}$ Based on the above analysis, this paper tries to improve the aforementioned "natural experiment" strategy to answer the following three concrete research questions. First, under the institutional circumstance of the Chinese university, would a close peer network help college student improve academic achievements? Second, if there is indeed an effect, what is the major mechanism of influence? Third, as time goes by, would the effect of original, randomly distributed peers increase or decrease?

Before proceeding to the literature review, the author would like to point out three basic standpoints that this paper has about peer social network. First, the past research on social capital focuses on both network closure (Coleman 1988) and network diversity, as, for example, in Structure Hole Theory (Burt 2001). The latter may have explanatory power in business studies, but it does not have such power in studies on educational attainment. Thus, as most research on academic achievement, this paper focuses on the influence of closed core networks. Second, there are many ways to define social capital from a network perspective, including tie strength, network size, network density, and characteristics of contacts. This paper emphasizes the influence of peer characteristics (academic ability) on a given student's academic achievement. Most research investigates the influence of peer capacity, so this focus helps with our dialogue with existing literature. Finally, the composition of peers is multivariate, consisting of classmates, clubmates, friends, those from the same hometown, those in the same study group, and so on. These peers, however, are most often not "randomly distributed," and therefore cannot overcome the endogeneity challenge. As such, this paper only emphasizes "roommates" out of all peer categories (see the " research strategy" section of this paper for more information). Although roommates cannot represent all peers in terms of effect, using this category enables us to bypass many methodological issues and directly get at a set of core topics of peer social capital, such as the causal effects of peer social capital, their mechanisms and dynamic changes, as well as group differences across different social class backgrounds.

\section{Literature review and hypotheses}

Research concerning the effect of peer social capital on academic achievement has had a long history (Haller and Butterworth 1960; McDill and Coleman 1965; Duncan et al. 1968; Davies and Kandel 1981; Ream and Rumberger 2008; Hasan and Bagde 2013). In The Adolescent Society, Coleman advances an important argument: there exists a subculture among adolescents distinct from adult culture, and as peers at the same age, adolescents are more likely to be influenced by each other. Moreover, the effect of peers on the student's achievement is even larger than that of teachers and the school (Coleman 1961:11). Coleman also believes that peer inputs, in which better students are put into the group of students with disadvantages, is a major solution to school issues (Coleman 1988). In a scholarly debate about social capital and academic

${ }^{2}$ In our interview with staff and students, about $98 \%$ of students choose to live in the dorm and keep living with the same roommates.

${ }^{3}$ See the "research strategy" section of this paper for more information. 
achievement published in American Sociological Review, the two sides both acknowledge the significant effect of peers on academic achievement (Morgan and Sorensen 1999; Carbonaro 1999). Rich (2009) even goes as far as to suggest that the only way parents can influence their children is to choose peers for them. Harris might be exaggerating, but his idea that peers are the important path of generational reproduction coincides with the Wisconsin School's emphasis on the effect of significant others.

On the other hand, scholars never stopped questioning the importance of peers. Specifically, after taking endogeneity into account, some scholars argue that the effect of peer social capital is weak, unstable, and even negligible (Foster 2006), or that it only holds under certain conditions (Zimmerman 2003; Stinebrickner and Stinebrickner 2006). Giordano's (2003) review of a large amount of literature concludes that the convergence of young people and their peers on multiple dimensions is mainly an endogenous effect due to homogeneity bias, whereas the effect of peer network takes a subordinate, secondary role. In other words, the effect is one of "birds of the same feather flock together," rather than one of "taking the behavior of the company." In this respective, if we are not careful about endogenous selection in socialization when talking about peer social capital, the conclusion could be pale regardless of its generalizability.

\section{The mechanism of peer effects}

In the face of debates and challenges, we must clearly formulate exactly how peer networks influence academic achievement of the student. In other words, what is the mechanism and the path by which peer networks influence academic achievement? Stinebrickner and Stinebrickner (2006) and Hasan and Bagde (2013) both divide the mechanism of influence of social capital on academic achievement into direct and indirect effects, but disagree on which effect is the major one. To keep with this vein of research, this paper is also based on this division between direct and indirect effects.

\section{Direct effect: actors directly mobilize social network resources to serve their goals}

The first perspective is that of network resource. It maintains that resources related to academic achievement that are embedded in peer networks are the major source of peer influence. Consider a student A, who has in his peer network a high-achieving student B. At this time, B becomes A's potential resource for emulation. When A is troubled by a difficult academic problem, or could not understand what the teacher said in class, he can find counsel in B. For test-taking purposes, A can obtain notes and key points from B. As such, the resource and skill that peers have become the student's network resource. To improve their own grades, students can mobilize resources of peer networks (Hasan and Bagde 2013). To this end, friend networks assert influences as considerable resources implicated in social networks continue to accumulate and interact, thereby influence the process of school and the final study outcome, as well as other societal outcomes. Therefore, most of this research falls into the theoretical framework of social capital (Ream and Rumberger 2008).

Generally speaking, such a view stresses the individual initiative and rationality, mobilization, and utilization of network resource to obtain social support and achieve targets (such as getting good grades). Traditionally, it is called the direct effect (Hasan and Bagde 2013). In fact, in labor market research, this is a rather common network 
perspective. For example, jobseekers would mobilize their social network to pursue development (Bian 1997; Lin 1999; Bian et al. 2015; Chen and Volker 2016).

Indirect effect: social networks shape an individual's values and behavior to affect outcomes The second perspective sees the effect of social networks on outcomes (including academic achievement) as indirect, through influencing the individual's values (such as educational and career expectation) and actions. Such an indirect effect is reflected in three aspects.

The first aspect is the effect of significant others. Peer networks are a core component of significant others and often fulfills the function of "the role model." It could determine the student's educational and career expectation, attitude towards school, and motivation for achievement and finally impact academic achievement (Haller and Butterworth 1960; Sewell et al. 1969; Buchmann and Dalton 2002). Compared with other factors, the social network comprised of peers and parents has stronger and more direct effect on molding motivation for achievement. This effect can even surpass that of talent, previous academic foundation, and the student's social background (Spenner and Featherman 1978). Sometimes, a significant other is also a potential "competitor," who stimulates the student's motivation for study. If the competitors in the social network study hard, the student will also be stimulated to work hard.

Second, social norms and sanctions that are culturally embedded in peer networks constrain individual action. Significant others can influence one's values similarly to value introjection (Portes 1998). However, the issue is that the actor does not necessarily agree with the mainstream value or modes of action in his friend circle. But if he does not conform to that subculture, he risks exclusion or punishment by other members (Coleman 1988). As such, social norms also push the actor to adopt a mode of action similar to that of members of the network and thereby causing similar outcomes of action.

Finally, research on social contagion and the bandwagon effect also finds that social networks provide the foundation for the diffusion of ideas and actions. People's emotions, physical and mental health, and social actions (especially negative ones) can diffuse from one to another, or even from one to another to yet another (Smith and Christakis 2008; Christakis and Fowler 2013). If the last perspectives have some trace of individual rationality, theory of social contagion shows that the convergence effect of networks can be an unconscious result. In conclusion, the indirect network effect manifests externally just like Adam Smith describes in The Theory of Moral Sentiments (2010/1759: 96-98) (Fig. 1).

The above graph demonstrates the basic difference between direct and indirect effects. The direct effect emphasizes how the actor mobilizes and utilizes resources in peer networks to obtain higher academic achievement, whereas the indirect effect stresses how peer networks shape the student's values and indirectly influence his academic achievement. Based on these two mechanisms, we propose the first hypothesis of this paper.

Hypothesis 1: The better the random assigned peers' grades, the better the given student's grades.

\section{Direct and indirect peer effect: which is more powerful?}

Does the direct or the indirect effect play the dominant role? This is an even more interesting research puzzle. Ideal-typically speaking, the direct effect emphasizes 


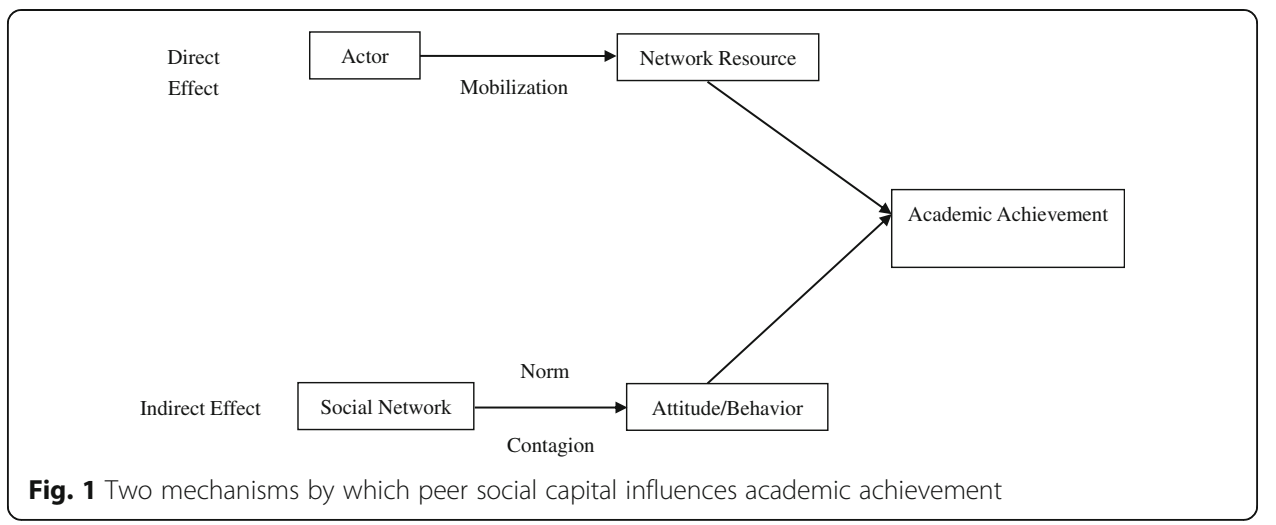

individual agency, rationality and the obtaining and utilizing of network resources, whereas the indirect effect sees social networks as social contexts external to the individual. The two effects themselves illustrate the sociological tension between structure and agency. Nevertheless, the two kinds of effects are often interwoven and hard to separate. Suppose student A has a peer, student B, who has a positive attitude towards school and outstanding grades. If and when we find that B has positively affected A's grades, it is still difficult to tell whether this effect comes from B's directly helping A with studying or from implicit influence that $\mathrm{B}$ has on $\mathrm{A}$.

Hasan and Bagde (2013)'s approach to this issue is heuristic. They assert that, in this scenario, if B's math grade only correlates with A's math grade, but not any other subject grade, then network resources-the direct effect-are at play. On the other hand, if B's math grade does not only affect A's math grade but also her other grades (e.g., English), then B does not only provide A with resources, but he also influences her attitudes and actions, which indirectly affect her academic achievement. In other words, in this case, both direct and indirect effects are at play. This strategy is called "resource matching." The authors find a positive effect of peers' math grades on the student's math and chemistry grades, but no effect on English grade. Moreover, peers' social science grades have very little effect on the student's math grade. They therefore conclude that the effect of peer networks on academic achievement comes from the direct, rather than the indirect, effect.

The conclusion is, however, open to doubts. First of all, the effects of peer social capital differ fundamentally in the fields of human and social sciences than in the field of natural sciences. In natural sciences, there is often a certain answer, more frequent communication and coordination, and therefore stronger and more immediately peer effect can be observed (Brunello et al. 2010). Second, Hasan and Badge's research actually confirms the aforementioned fact: peers' social science grades do not have an effect on the student's social science grades, but have significant effect on his physics and chemistry grades. Furthermore, research has revealed that the major influence of peer networks is the communication of general skills (such as strategies for study), rather than knowledge of specific areas (Griffith and Rask 2014). Finally, other studies have found that peers' negative social behaviors (such as alcoholism and extensive gaming) also negatively affect the student's grades (Stinebrickner and Stinebrickner 2006; Kremer and Levy 2008). All these studies illustrate how peer networks indirectly influence the generation of human capital through shaping the individual's preference and ideology. 
Based on this debate, we propose a pair of competing hypotheses:

Hypothesis 2-1: The direct effect is the dominant mechanism by with peer social capital affects academic achievement.

Hypothesis 2-2: The indirect effect is the dominant mechanism by with peer social capital affects academic achievement.

Since peer effect varies among majors in humanities, social sciences, and natural sciences, a major-matching instead of a subject-matching approach will be used to test these two competing hypothesis. The "research strategy" section will elaborate more on this.

\section{Strengthen or weaken: time effects of peer social capital}

Most relevant international studies show a weakening of peer effects with time. In the study of randomly assigned roommates, Sacerdote (2001) finds peer effects only on the student's academic achievement in the first year. Hasan and Bagde (2013) also finds that the average effect of roommates is present only in the second semester, and the effect of roommates in the top $20 \%$ in terms of grades can stay until the third semester. By the fourth term, neither average nor partial peer effects remain.

Strictly speaking, the social context that this paper strives to observe and analyze is not directly comparable to the aforementioned studies. European and American colleges usually only require new freshmen to live on campus. By their sophomore year, most students find off-campus living and roommates by themselves. In the India universities that Hasan and colleagues studied, the roommate relationship was maintained for one year, too. But the present study would investigate roommate relations that continue until students graduate from college. These relations are closer and more stable. Although the two kinds of roommate relations are not directly comparable, the context of this study has unique value-it allows us to test whether effects from randomly assigned peers change with time.

But would the effects strengthen or weaken? Theoretically speaking, both are possible. On the one hand, as time goes by, roommates interact more, strengthening their mutual beneficial relation. As their peer relation strengthens, we have reason to believe their mutual influences strengthen, too. On the other hand, in the course of time, the student's social network keeps expanding and goes beyond their dorm, or even class and major. They would have more opportunity to get to know friends with similar interests. In other words, as "new students" become "old students," they would not stop at socializing with the friends they were "assigned to," but look for birds with similar feathers in a broader space. At this time, we can also reasonably infer that the effect of original, randomly assigned peers would weaken. As such, we propose another pair of competing hypotheses:

Hypothesis 3-1: In the course of time, the effects of original, randomly assigned peers will strengthen.

Hypothesis 3-2: In the course of time, the effects of original, randomly assigned peers will weaken.

\section{Social class matters: moderating effects on peer social capital}

The university is a peculiar field consisted of students from all social class backgrounds, and the random assignment of roommates further breaks down class-based segregation. 
To some extent, the pattern of homogeneity in socialization is broken. As such, the final focus of this paper is whether there exist class differences in the effect of peer networks. This question can be further dissected into two sub-questions. First, does peer social capital affect students from different class backgrounds in the same way? Second, do peers from different class backgrounds bring about the same effect?

Investigation into these two questions can help us understand the relationship between social networks and inequality. Recent studies of social capital and the reproduction of inequality have clearly revealed the importance of network-based social capital as a microlevel mechanism by which social structure and inequality reproduce (DiMaggio and Garip 2012; Lu et al. 2013; Cheng and Bian 2014; Cheng et al. 2015). In this research, social networks are endogenous products of social structure. In the present study, however, we look at another meaningful topic: could intentional alteration to social networks (random dorm assignment) change the pattern of the reproduction of social inequality?

\section{Research strategy}

As research on social networks bloom, how to accurately identify causal effects of social networks has become a widely shared concern in the subfield (Mouw 2006; Liang 2010; Chen and Fan 2011; Sacerdote 2013). Three challenges confront the accurate identification of the network effect of academic achievement: selection bias, common environmental factors, and the reflection problem. In fact, these difficulties do no only confront research on educational achievement, but they are also reflected to certain degrees in all research areas related to network effects (e.g., job-seeking, health). As such, how to effectively solve these problems and successfully identify network causal effects is a shared concern of social scientists (Sacerdote 2014). In the following sections, I explain how this study deals with the three technical difficulties.

\section{Capturing the causal effect of peer social networks}

\section{Selection bias and its solution: a natural experiment with random assignment}

Among the aforementioned three challenges, selection bias is the most serious (Sacerdote 2011). Selection bias reflects homophily in socialization-birds of a feather flock together. In other words, people are more likely to tie and befriend with others who are similar to themselves. In terms of academic achievement, friends might be similar in grades, study habits, personality, or even intellectual factors. Therefore, the correlation between the student's grade and his friends' is not a causal relation. ${ }^{4}$ More difficult still, factors causing homophily can be either explicit and observable or implicit and unmeasurable. Statistical strategies of controlling (such as regression analysis and propensity score matching) cannot achieve perfect control or balance since there can be countless causes of selection bias (Mouw 2006).

Natural experiment is a new method for overcoming endogeneity and investigating causal effects between variables. Causal analysis has two major traditions: "controlling" and "random experiment" and the latter is widely considered as the "golden standard" of causal analysis (Austin 2011). In social sciences, though, multiple factors make it difficult for us to examine causal relations by experiment, and most studies amend the

${ }^{4}$ For a review on network homophily, see McPherson et al. 2001. 
problem by measures such as after-the-fact statistical controlling, matching, and looking for instrumental variables. Different from these approaches, natural experiment inherits from the experiment method, the emphasis on preemptive randomization that is not incentivized or intervened by the research project, but by other external social forces such as governmental or organizational policies. In other words, certain policies randomly group people into different categories and incur different treatments, and such a differential treatment caused by external factors just happens to constitute the kind of intervention that the researcher cares about. At this time, the researcher can make causal inferences by comparing intergroup variations caused by intervention. ${ }^{5}$ For example, the institutional design of random roommate assignment provides researchers with a great platform for natural experiment to observe the existence and degree of peer social capital effects. To help new freshmen adapt to campus life and strengthen the guidance to and management of the new students, most universities require freshmen to live on campus. In most cases, between two and four freshmen are assigned to each dorm room. Aside from gender, roommate assignment is close to random assignment (Sacerdote 2001; Zimmerman 2003). Under this random assignment principle, new students from all over the country and different backgrounds form new social networks. In the process, not only are research subjects preemptively randomized, but the "intervention" (characteristic of peers) is also randomized. The researcher believes that this mode of distribution breaks selective bias in social interaction, and randomizes invisible factors. Similar natural experiments include examining the causal effect of property rights on poor families using land distribution and its continuous conflicts in Argentina (Galiani and Schargrodsky 2010). In the public health field, scholars have begun to use natural experiments like employment opportunity, housing policy, and tobacco price fluctuation to evaluation causal effects of the respective intervention on residents' health (Petticrew et al. 2005).

In solving the selection problem, natural experiment based on random assignment has so many advantages (Cheng 2015) that it is considered as the cleanest estimation to capture network causal effects (Mouw 2006). But notice, natural experiment is not completely randomized experiment, and it also needs to be evaluated on validity. The most important standard is the degree of "as-if randomness" (Dunning 2012: 235-244). ${ }^{6}$ For example, in the above case, students can pose some requirements about their roommates (such as if they are willing to live with students who stay up late, play music, have pets, or smoke), which influences the degree of randomization. The fewer such factors, the higher the degree of as-if randomness, and the closer it is to a randomized controlled trials (RCTs) in design.

This paper borrows from the natural experiment strategy of random roommate assignment. We have chosen all freshmen of class 2012 of a Chinese comprehensive university (hereafter "University C") as research subjects. It successfully avoids research biases, especially the Hawthorne Effect, because there is no direct interaction between the college students and the researchers. University $C$ ranks among the top 5\% of all universities in mainland China. On a national scale, students of this university have very strong academic ability. Strictly speaking, analytical conclusions from the present

\footnotetext{
${ }^{5} \mathrm{~A}$ shared characteristic of natural experiment and instrumental variable is their chance-happening. In China's transitional period, local governments and agencies launched numerous reform and experimentation, which create a rare opportunity for researchers and for knowledge accumulation.

${ }^{6}$ For more details, see Dunning 2012 "Natural experiment in Social Sciences."
} 
study should only be extended to universities similar to University $C$ and ranking in the first tier. Compared with relevant research on European and American colleges, this study has four unique advantages. First, it has a higher level of randomization. In European and American colleges, dorm room assignment considers a great deal of student demands, but University C assigns dorm rooms only based on the student's college, gender, and last name's alphabetical order. Second, the scope of dorm network is larger. Each dorm room in University $\mathrm{C}$ houses anywhere from three to six students, whereas most European and American universities have two-person dorm rooms. Per Simmel's assertion that a triadic relation is social network in its true meaning, the dorm network of University $\mathrm{C}$ can better reflect social network effects. Third, roommate relationships last longer. European and American universities only require first-year students to live on campus, while students of University $C$ live with the same roommates for the entire duration of college. This enables us to capture long-term effects of peer social capital. Fourth, roommates have a closer relationship. Whereas only 37\% of American college students list their roommate as one of their three best friends (Stinebrickner and Stinebrickner 2006), our interview and sample survey with students of University C reveals that most dorm roommate relationships develop rapidly from strangers into strong ties ${ }^{7}$ much closer to the bonding relationship that Coleman formulates.

\section{The confounder of common environments and its solution}

The confounder problem refers to the fact that the outcomes are not affected by members of the network, but the result of the actor and members of his network being exposed to the same natural or social environment. For example, because the student and his peers are often in the same class, observed correlation between the student's grade and that of peers-even if we could rule out selection bias-might have resulted from differences in teachers' quality or teaching style, or unequal distribution of other educational resources to different classes, instead of from peer effects.

As for the present study, there exist natural and social shared environments, and both may influence our estimation of the social capital effect on academic achievement. The natural context here includes internal (such as material conditions like self-studying space) and external environment (such as the distance to classrooms or to raucous street) of different dormitory buildings. Variations in these factors can affect the academic achievement of students living in different dorm buildings, causing an overestimation of social network effects. Following conventional practice (Sacerdote 2001), we include all dorm buildings as dummy variables in the model to control building differences. As to the social environments, all students in the study are in 75 different majors, and grades are not comparable across majors. But about two-thirds of dorm roommates are in the same major, and so to use grades as the index of academic achievement may cause an overestimation of social network effects. Therefore, we use scholarship reception as the index of academic achievement. Scholarships in University $\mathrm{C}$ are selected through the following process. Each major department is given a quota for possible scholarships according to the scope of students in the department. Then, the department awards scholarships based on students' ranking of general grades in the

${ }^{7}$ When asked to "evaluate your relationship with roommates," $87 \%$ of students of University C reported "very good," while only $0.4 \%$ reported "very bad." When listing their three best friends, $76.2 \%$ of the students wrote down at least one of their roommates. 
last school year. As such, scholarships factually represent general grades standardized by major.

\section{The reflection problem and its solution}

The issue of reflection is especially salient in research on peer effects. Namely, just as peers influence the student's academic achievement, the student also influences his peers' academic achievement. When such synchronicity problem exists, cross-sectional data often fails to get as unidimensional causal relations, and longitudinal data is needed to identify temporal orders. ${ }^{8}$ Relative to the isomorphism in other observable and unobservable characters, the reflection problem is rather easy to solve. Moreover, the precondition of reflection is precisely the existence of peer effects.

In previous research, international scholars often use network members' college entrance exam (CEE) scores as the explanatory variable to circumvent the issue of the reflection problem. But in the Chinese case, the CEE score is not an apt explanatory variable. The reason is threefold. First, the mode of study in Chinese high schools differs significantly from that in universities. Grades in the high school stage are inadequate in representing the network member's current academic ability and attitude. Second, a good number of students did not enter university through the CEE (directly submitted students are an example), and so do not have a CEE score. Furthermore, students' CEE scores are confidential information in University $\mathrm{C}$, and so we could not obtain that data. This paper therefore uses peers' first-year academic performance (whether they received scholarships) as the explanatory variable ${ }^{9}$ and the given student's first-year performance as the preintervention variable to predict the given student's second- and third-year academic performance (whether he receives scholarship). ${ }^{10}$

\section{Distinguishing direct and indirect effects}

Another core aim of this paper is to distinguish between the direct effect and the indirect effect in the peer network effects on academic achievement. Traditional strategy is to directly survey and measure the social resource that the actor has mobilized (Bian et al. 2015), but the official data we are using does not contain any information on the actor's action or incentive. Moreover, even if we surveyed the students, we would not be able to exhaust all mobilizing processes and resource types and therefore would not be able to objectively tell exactly which effect takes the dominant role.

The paper maintains that despite problems with the major-matching strategy, the "resource-matching strategy" is a valuable construct. This paper uses the unique institutional context of Chinese universities to improve this method and tries to use major matching to distinguish between direct and indirect effects.

To be more specific, considering the first year in University $\mathrm{C}$ is for general education, and major classes start in the sophomore year, we believe that academic advantages and resources of peers majoring in other subjects cannot become the student's academic resource. At this time, peers in different majors may only exert the indirect, rather than

\footnotetext{
${ }^{8}$ It is better if pre-measured data is collected before the student and peers meet. High academic performance is an example. For a detailed explanation on the reflection problem, see Manski (1993).

${ }^{9}$ Network members' first-year academic performance could be affected by the reflection effect, causing us to overestimate network effects. But the analysis that follows shows that network effects strengthen in the course of time. As such, first-year reflection effect should be quite weak.

${ }^{10}$ Fourth-year grades are not considered in scholarship evaluation (because the student would have left the university) and therefore is not included in this paper's analysis.
} 
direct, effect. However, network members in the same major may wield complex influence including both direct and indirect effects. Therefore, an interaction term of the peer's academic ability and whether the peer and the student are in the same major can help us distinguish between direct and indirect effects of social capital.

\section{Data and variables}

We cleaned and reduced the official data to 3679 students by removing dropouts (1.6\%), commissioned students, joint-degree students, international students, and exchange students, as they usually enroll for a shorter time and are not entitled to scholarships. Seventy-eight students $(2.1 \%)$ were not living on campus because they were studying abroad or for other special reasons. Another 45 had less than two roommates. All of them were eliminated from the analysis. A total of 3578 students in the first-year cohort are included in the final sample. Table 1 displays the descriptive information of key variables.

\section{Findings}

Descriptive statistics

First of all, we describe the effect of roommates' first-year academic performance on the student's second- and third-year performance from two angles (see Fig. 2). In the first perspective, we understand the dorm room as a social context to sort out how individual grade changes in different contexts. A student who did not receive scholarship in the first year and has no roommate who received scholarship in the first year either has a $44.2 \%$ probability to receive scholarship in the second year, and a $45.6 \%$ probability to receive scholarship in the third year. If, on the other hand, all the student's roommates received scholarships in the first year, the student's probability to receive scholarship would be $70.5 \%$ in the second year and $71.4 \%$ in the third year. In the second scenario, the probability is double that in the first scenario. Similarly, if a student who received scholarship in the first year but his roommates did not, he has a $24.6 \%$ probability to receive scholarship in the second year, and a $20.5 \%$ probability to receive scholarship in the third year. If all his roommates also received scholarships in the first year, the student's probability to receive another scholarship would be $45.8 \%$ in the second year and $43.7 \%$ in the third year. Generally speaking, an individual's academic performance changes with the academic environment in the dorm.

Table 1 Summary statistics for key variables

\begin{tabular}{llllll}
\hline Variables & Obs. & Mean & S.D. & Notes & \\
\hline Awarded (1st year, self) & 3578 & 0.43 & 0.495 & $0=$ No & $1=$ Yes \\
Awarded (2nd year, self) & 3578 & 0.431 & 0.495 & $0=$ No & $1=$ Yes \\
Awarded (3rd year, self) & 3578 & 0.429 & 0.495 & $0=$ No & $1=$ Yes \\
Awarded (1st year, roommate) & 3578 & 0.428 & 0.493 & $0=$ No & $1=$ Yes \\
Female & 3578 & 0.313 & 0.464 & $0=$ No & $1=$ Yes \\
Ethnic Han & 3578 & 0.928 & 0.258 & $0=$ No & $1=$ Yes \\
CPC membership & 3578 & 0.083 & 0.276 & $0=$ No & $1=$ Yes \\
Low-income family & 3578 & 0.344 & 0.475 & $0=$ No & $1=$ Yes \\
Same major as roommate & 10,044 & 0.64 & 0.48 & $0=$ No & $1=$ Yes \\
Number of roommates & 3578 & 2.902 & 0.313 & Min. $=2$ & Max. $=5$ \\
\hline
\end{tabular}




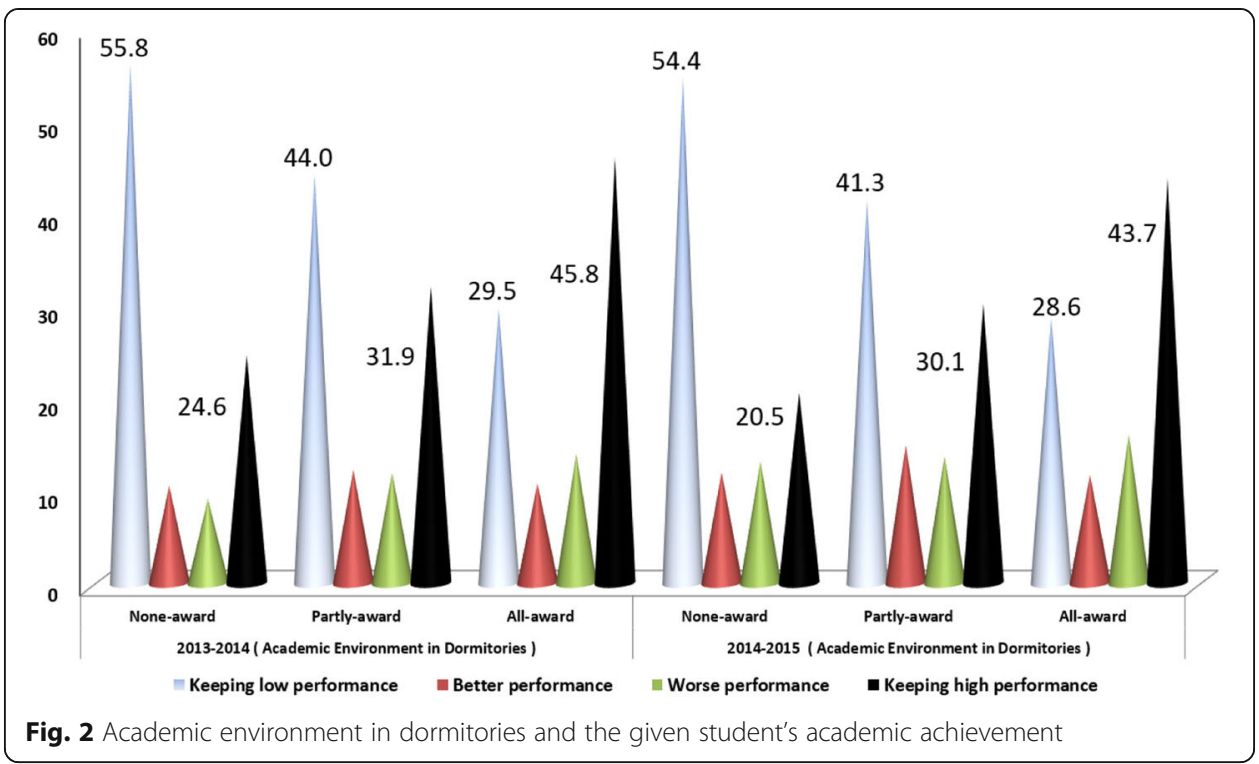

We can also analyze the effect of peers' first-year performance by turning data on the student and his roommates into dyadic data. When no roommate received scholarship, the probability for the given student to fail again in the second year to get scholarship is $49.4 \%$, while that for him to get another scholarship in the second year is $28.1 \%$. When all roommates received scholarships, the probability for the given student to fail again in the second year to get scholarship falls to $28.1 \%$, while that for him to get another scholarship in the second year rises to $36.5 \%$. The effects in the third year are very similar to those in the second year. ${ }^{11}$

In general, descriptive statistics show strong positive effects of roommates' first-year academic performance on the given student's second- and third-year academic performance that are stable over time. Hypothesis 1 is preliminarily supported.

\section{Regression analysis}

\section{Social capital effect on academic performance and time trends}

Models $1-3$ in Table 2 are a set of logistic regression models on the student's second-year scholarship status. In model 1, the student's gender and first-year performance are controlled. The percentage of peers who received scholarship in their first year significantly influences the student's second-year performance $(p<0.05)$. Model 2 added the student's college into the control. The percentage of peers who received scholarship in their first year still significantly influences the student's second-year performance, but the level of significance has fallen $(p<0.1)$. In model 3 , we transformed the data structure into paired $\mathrm{data}^{12}$, and the results are the same as those of models 1 and $2(p<0.05)$. Comparing the coefficients, standard

\footnotetext{
${ }^{11}$ All variations mentioned here passed the significance test. Please direct requests for more specific statistics (including descriptive statistics of variables) to the authors.

${ }^{12}$ In social network analysis, to differentiate different alters' effect on the ego, the analyst often expands the data from a "configuration"-based structure into a "relation"-based structure, i.e., turning a horizontal table into a vertical one. This can also be understood as having multiple replications of one ego, each corresponding to one alter. Because repeated uses of one case under this scenario, the assumption of intercase independence no longer holds. According to tradition, we adjusted the standard deviations of the logistic regression for each observation. In Stata, the option is "cluster" (see Burt and Burzynska 2017).
} 
Table 2 Peer social capital effect on academic achievement and time trend

\begin{tabular}{|c|c|c|c|c|c|c|}
\hline \multirow[t]{2}{*}{ Variable } & \multicolumn{3}{|c|}{ Awarded in 2nd year } & \multicolumn{3}{|c|}{ Awarded in 3rd year } \\
\hline & (1) & $(2)$ & (3) & (4) & (5) & (6) \\
\hline \multicolumn{7}{|l|}{ Controlled variables } \\
\hline Female & $\begin{array}{l}0.594^{* * *} \\
(0.087)\end{array}$ & $\begin{array}{l}0.670^{* * *} \\
(0.150)\end{array}$ & $\begin{array}{l}0.710^{* * *} \\
(0.151)\end{array}$ & $\begin{array}{l}0.573^{* * *} \\
(0.082)\end{array}$ & $\begin{array}{l}0.738^{* * *} \\
(0.143)\end{array}$ & $\begin{array}{l}0.745^{* * *} \\
(0.144)\end{array}$ \\
\hline Awarded (1st year, self) & $\begin{array}{l}2.344^{* * *} \\
(0.081)\end{array}$ & $\begin{array}{l}2.304^{* * *} \\
(0.083)\end{array}$ & $\begin{array}{l}2.304^{* * *} \\
(0.084)\end{array}$ & $\begin{array}{l}1.845^{* * *} \\
(0.076)\end{array}$ & $\begin{array}{l}1.797^{* * *} \\
(0.078)\end{array}$ & $\begin{array}{l}1.798^{* * *} \\
(0.079)\end{array}$ \\
\hline Ethnic Han & & $\begin{array}{l}0.667^{* * *} \\
(0.176)\end{array}$ & $\begin{array}{l}0.645^{* * *} \\
(0.157)\end{array}$ & & $\begin{array}{l}0.825^{* * *} \\
(0.170)\end{array}$ & $\begin{array}{l}0.809^{* * *} \\
(0.162)\end{array}$ \\
\hline CPC member & & $\begin{array}{l}0.354^{*} \\
(0.148)\end{array}$ & $\begin{array}{l}0.373^{*} \\
(0.153)\end{array}$ & & $\begin{array}{l}0.129 \\
(0.140)\end{array}$ & $\begin{array}{l}0.134 \\
(0.145)\end{array}$ \\
\hline Low-income family & & $\begin{array}{l}0.417^{* * *} \\
(0.089)\end{array}$ & $\begin{array}{l}0.414^{* * *} \\
(0.090)\end{array}$ & & $\begin{array}{l}0.376^{* * *} \\
(0.084)\end{array}$ & $\begin{array}{l}0.372^{* * *} \\
(0.085)\end{array}$ \\
\hline $\begin{array}{l}\text { Dorm building (19 } \\
\text { dummy variables) }\end{array}$ & & Yes & Yes & & Yes & Yes \\
\hline \multicolumn{7}{|l|}{ Explanatory variables } \\
\hline $\begin{array}{l}\text { Award percentage (1st } \\
\text { year, roommate) }\end{array}$ & $\begin{array}{l}0.289^{*} \\
(0.128)\end{array}$ & $\begin{array}{l}0.245 ! \\
(0.131)\end{array}$ & & $\begin{array}{l}0.523^{* * *} \\
(0.121)\end{array}$ & $\begin{array}{l}0.476^{* * *} \\
(0.125)\end{array}$ & \\
\hline $\begin{array}{l}\text { Awarded (1st year, } \\
\text { roommate) }\end{array}$ & & & $\begin{array}{l}0.121^{*} \\
(0.052)\end{array}$ & & & $\begin{array}{l}0.190^{* * *} \\
(0.050)\end{array}$ \\
\hline Intercept & $\begin{array}{l}-2.260^{* * *} \\
(0.133)\end{array}$ & $\begin{array}{l}-3.499^{* * *} \\
(0.332)\end{array}$ & $\begin{array}{l}-3.557^{* * *} \\
(0.326)\end{array}$ & $\begin{array}{l}-2.104^{* * *} \\
(0.126)\end{array}$ & $\begin{array}{l}-3.551^{* * *} \\
(0.319)\end{array}$ & $\begin{array}{l}-3.412^{* * *} \\
(0.317)\end{array}$ \\
\hline N & 3578 & 3578 & 10,044 & 3578 & 3578 & 10,044 \\
\hline Pseudo $R^{2}$ & 0.226 & 0.241 & 0.240 & 0.161 & 0.179 & 0.174 \\
\hline
\end{tabular}

Standard deviation is in parentheses

$p<0.1 ;{ }^{*} p<0.05 ;{ }^{* *} p<0.01 ;{ }^{* * *} p<0.001$

deviations, and significant levels of control variables in model 2 and model 3, structural transformation of the data does not change the empirical results.

Models 4-6 are a set of logistic regression models on the student's second-year scholarship status. All three models show strong influences by peers' first-year scholarship reception on the student's third-year performance. Significance level shows that roommates' influence is stronger in the third year $(p<0.001)$. Third-year coefficients are about double of those in the second year, although this difference is statistically insignificant. What these results reveal is that in the course of time, the effect of original, randomly assigned peers continues to exist and even strengthens. Hypotheses 1 and 31 are supported.

In addition, for second-year academic performance, the effect of percentage of peers who received scholarships in the first year is about $10.6 \%$ of the effect of the student himself $(0.245 / 2.304)$, but for third-year performance, the ratio increases to $26.5 \%$ (0.476/1.797), 1.5 times the strength of influence in the second year. These results, from another angle, show increasing effect of peer social capital.

Table 2 also shows that female college students have better academic performance than their male counterparts, and Han students perform better than students from other minority ethnic groups. Being a member of the Communist Party of China (CPC) also has a positive influence on academic grades, but this effect plummets over time. College students from less economically privileged families have higher academic achievement, an understandable outcome that differs from relevant research on middle and primary schools. On the one hand, scholarships can ease some burden on the 
family, so poorer students are more motivated to get scholarships. On the other hand, students from weaker backgrounds strive more to accumulate human capital as a way to improve their future competitiveness on the job market. In the robust test, we include the 75 majors as dummy variables into the six models in Table 2. None of the models did the significance levels of peer network effects change, and the coefficients only change slightly. ${ }^{13}$

\section{Decomposing peer social capital effects on academic achievement}

Table 3 tries to decompose peer social capital effects on academic achievement into direct and indirect effects. According to foregoing analyses, we believe that a peer in the same major as the student can affect the latter both directly through providing study resources and support, and indirectly through influencing the student's value and behavior. But when the peer and the student are in different majors, it is possible that only the indirect effect is at play, as the peer would not be able to directly provide study help or knowledge material to the student. Based on this consideration, we have introduced a variable indicating whether or not the peer and the student are in the same major and conducted an interaction analysis with the peer's first-year scholarship reception. The result shows no significant difference between the effect of same-major peers and that of different-major peers on either the second-year or the third-year performance. In other words, despite the possibility for them to give direct help, samemajor peers do not have significantly higher influence on the student. It can be inferred that the effect of peer social capital is delivered through shaping the values and behaviors of the student. Hypothesis 2-2 is supported and Hypothesis 2-1 is not.

\section{Moderating effects of social class on peer social capital}

Annual family household income is used as an indicator of a student's social class background. Models 1 and 3 in Table 4 both show little class difference in the effects of peer social capital, though low-income students tend to have better academic records, that is, peer social capital has the same influence on poor student and others.

However, there is a significant difference between the effect of peers from the same class background as the student and that of peers from a different class background. First, model 2 in Table 3 shows a positive and significant effect from peers with a different class background on the student's second-year academic performance, but insignificant effect from those with the same class background. For third-year performance, model 3 shows continuous positive and significant effect of peers from different classes, with little change in the coefficient and significance. But the effect from same-class peers increases considerably and surpasses that from different-class peers in terms of both strength and significance.

The foregoing results show that, no matter if randomly assigned peers are from the same social background as the student or not, they have influences on the student's academic achievement. As time goes by, however, the student is more likely to identify with and mutually affect those peers from similar social backgrounds as himself.

\footnotetext{
${ }^{13}$ Due to limited space, we have not reported results of the robust test. Please direct requests to the author if interested.
} 
Table 3 Decomposition of peer social capital effect on academic achievement

\begin{tabular}{|c|c|c|c|c|}
\hline \multirow[t]{2}{*}{ Variable } & \multicolumn{2}{|c|}{ Awarded in 2nd year } & \multicolumn{2}{|c|}{ Awarded in 3rd year } \\
\hline & (1) & & $(2)$ & \\
\hline \multicolumn{5}{|l|}{ Controlled variables } \\
\hline Female & $0.720^{* * *}$ & $(0.151)$ & $0.746^{* * *}$ & $(0.144)$ \\
\hline Awarded (1st year, self) & $2.307^{* * *}$ & $(0.084)$ & $1.801^{* * *}$ & $(0.079)$ \\
\hline Ethnic Han & $0.654^{* * *}$ & $(0.157)$ & $0.811^{* * *}$ & $(0.162)$ \\
\hline CPC member & $0.372^{*}$ & $(0.153)$ & 0.133 & $(0.145)$ \\
\hline Low-income family & $0.412^{* * *}$ & $(0.090)$ & $0.372^{* * *}$ & $(0.085)$ \\
\hline Dorm building (19 dummy variables) & Yes & & Yes & \\
\hline \multicolumn{5}{|l|}{ Explanatory variables } \\
\hline Same major (reference: different major) & 0.081 & $(0.088)$ & 0.070 & $(0.082)$ \\
\hline Awarded (1st year, roommate) & 0.041 & $(0.086)$ & $0.235^{* *}$ & $(0.081)$ \\
\hline Awarded (1st year, roommate)* same major & 0.130 & $(0.107)$ & -0.069 & $(0.102)$ \\
\hline Intercept & $-3.620^{* * *}$ & $(0.332)$ & $-3.457^{* * *}$ & $(0.322)$ \\
\hline N & 10,044 & & 10,044 & \\
\hline Pseudo $R^{2}$ & 0.240 & & 0.174 & \\
\hline
\end{tabular}

Standard deviation is in parentheses

' $p<0.1 ;{ }^{*} p<0.05 ;{ }^{* *} p<0.01 ;{ }^{* * *} p<0.001$

\section{Conclusions}

Different from the numerous studies that focus on family social capital and academic achievement, this paper examines the effects of peer social capital. Using the official data from a Chinese university and taking into consideration endogeneity and other issues, this paper finds a significant effect of peers' academic ability on college students'

Table 4 Moderation effects of social class on peer social capital

\begin{tabular}{|c|c|c|c|c|}
\hline \multirow[t]{2}{*}{ Variable } & \multicolumn{2}{|c|}{ Awarded in 2nd year } & \multicolumn{2}{|c|}{ Awarded in 3rd year } \\
\hline & $(1)$ & $(2)$ & (3) & (4) \\
\hline \multicolumn{5}{|l|}{ Controlled variables } \\
\hline Female & $0.711^{* * *}(0.151)$ & $0.713^{* * *}(0.151)$ & $0.744^{* * *}(0.144)$ & $0.743^{* * *}(0.144)$ \\
\hline Awarded (1st year, self) & $2.305^{* * *}(0.084)$ & $2.305^{* * *}(0.084)$ & $1.797^{* * *}(0.079)$ & $1.797^{* * *}(0.079)$ \\
\hline Ethnic Han & $0.644^{* * *}(0.157)$ & $0.646^{* * *}(0.157)$ & $0.810^{* * *}(0.162)$ & $0.809^{* * *}(0.162)$ \\
\hline CPC member & $0.372^{*}(0.153)$ & $0.374^{*}(0.153)$ & $0.134(0.145)$ & $0.133(0.145)$ \\
\hline Low-income family & $0.377^{* * *}(0.102)$ & $0.410^{* * *}(0.090)$ & $0.402^{* * *}(0.096)$ & $0.376^{* * *}(0.085)$ \\
\hline Dorm building (19 dummy variables) & Yes & Yes & Yes & Yes \\
\hline \multicolumn{5}{|l|}{ Explanatory variables } \\
\hline Awarded (1st year, roommate) & $0.091(0.067)$ & & $0.212^{* * *}(0.062)$ & \\
\hline $\begin{array}{l}\text { Awarded (1st year, roommate)* poor } \\
\text { family }\end{array}$ & $0.085(0.107)$ & & $-0.066(0.103)$ & \\
\hline \multicolumn{5}{|l|}{ Awarded (1st year, roommate) } \\
\hline Different social class background & & $0.160^{*}(0.072)$ & & $0.160^{*}(0.069)$ \\
\hline Same social class background & & $0.097(0.061)$ & & $0.207^{* * *}(0.058)$ \\
\hline Intercept & $-3.545^{* * *}(0.325)$ & $-3.561^{* * *}(0.326)$ & $-3.421^{* * *}(0.317)$ & $-3.409^{* * *}(0.317)$ \\
\hline N & 10,044 & 10,044 & 10,044 & 10,044 \\
\hline Pseudo $R^{2}$ & 0.240 & 0.240 & 0.174 & 0.174 \\
\hline
\end{tabular}

Standard deviation is in parentheses ! $p<0.1 ;{ }^{*} p<0.05 ;{ }^{* *} p<0.01 ;{ }^{* * *} p<0.001$ 
human capital accumulation. Our finding differs from that of relevant research in other countries in several ways. First, the mechanism of peer social capital effect operates through an indirect rather than direct channel. In other words, peer networks affect the given student's final academic outcome indirectly, by shaping his/her value and behavior instead of offering academic support directly. Second, in the course of time, the effect of randomly assigned original peers stays stable and shows an increasing trend over time. Additional analysis reveals that the source of that increasing trend are peers from similar social class background as the student himself, while the effect from peers with different social background stays stable. In addition, for students with different social class backgrounds, the effect of peer social capital differs little.

The paper has two major contributions. First, we provide a new explanation for the fundamental debate about whether randomly assigned peers have network influence. International research about how peer social capital fosters human capital contains a fundamental debate: whether randomly assigned peers have network effect at all. Although most scholars make use of "natural experiments" based on random assignment similar to this paper, some finds a strong effect, while others find a weak effect, and yet others claim that effect does not exist (Sacerdote 2011). Most of the research, however, is limited by the institutional context in which random assigned peer relationships only last for a year before disappearing in the institutional level. The institutional context in University $C$, examined in the present study, is entirely different-random assigned peer relationships last for several years. Based on this unique institutional context, this study finds an observable but unstable peer effect when the peer relation is one-yearold (significant at the statistical level of 0.1), which becomes strong and stable after the first year. In sum, the effect of peer social capital on academic achievement depends on how long the peer relation lasts. Taken together, we argue that research finding from other countries of an unstable effect is highly likely related to institutional-contextual limitations, i.e., relative short duration of peer relationships. Therefore, future research should take the duration of peer relationships with random assignment into account.

Second, by improving the research design, this paper examines the mechanism of influence of peer social capital and arrives at a conclusion contrary to previous ones. Hasan and Bagde (2013) first propose the method of "resource matching" to test direct and indirect effects and find that the direct effect is the major source of peer social capital. But in human and social sciences, peer social capital effect plays out differently than it does in natural sciences (Zimmerman 2003; Brunello et al. 2010), casting doubts on their conclusion. Some other studies have revealed possible dominant role of the indirect effect (Stinebrickner and Stinebrickner 2006). This paper improves the resourcematching method using the unique institutional context of Chinese universities. We propose "major-matching" as a method to distinguish between direct and indirect effects. Building on this, we find that the major source of peer social capital is the indirect effect rather than the direct effect.

Why does the indirect channel matter? This problem is, in fact, not hard to understand. The direct effect entails a presumption: that individuals are school-oriented rational actors and see their peer networks on this basis. This presumption often does not hold. Peer networks serve multiple functions-they can be oriented to school, entertainment, or emotion (Ream and Rumberger 2008). For instance, when investigating the "climate of value" among students, Coleman finds a good number of students are 
more concerned with their appearance than grades that they are more willing to become celebrities or athletes (Coleman 1961). Research in the Chinese context also has similar findings - that peer network size and tie strength are negatively correlated with the stock of the given student's knowledge (Cheng 2012). The newest survey data of ours shows similar circumstance: only $24 \%$ of correspondents often "study together" with their roommates, but a whopping $71 \%$ often "relax or entertain" with their roommates. From this perspective, to see peers' academic ability as a resource might be nothing more than a scholarly speculation. To take a step back, even if students see their peer networks from a pure school orientation, they would "selectively" construct and develop networks that contain the resources they need. Therefore, under random assignment, it is usually difficult to establish the direct effect, while the indirect effect, because of its emphasis on the externality of network effects and limited space for individual rationality, shows significant influence.

There are certain shortcomings in the research strategy of natural experiment based on random roommate assignment. Most of this research focuses on highly selective groups, making it difficult to infer about other groups based on the conclusion. More importantly, this kind of highly selective groups is often extremely homogeneous groups. If we look at highly heterogeneous groups, peer networks may no longer have any effect (Stinebrickner and Stinebrickner 2006). This is a crucial challenge as the real world is apparently more heterogeneous. Realizing the problem, this paper examines social class variation. The analysis shows an increasingly strong peer effect from peers with similar class background as the student, and a stable effect of those from different classes in the course of time. The relevance of this conclusion is twofold. First, it shows heterogeneous groups can also affect each other. Second, we can infer that policy interventions into social networks can actually produce policy effects. In recent years, the national college admission system has seen frequent adjustments such as the addition of the special admission program for poor regions. These have created for scholars a research context that is more heterogeneous and contains more diverse network constructs. These new changes can help with relative research.

Numerous puzzles concerning peer networks still await investigation. First, from the policy perspective, we need to examine whether the effect of peer social capital is nonlinear. In other words, is the effect by high academic ability students on lower academic ability students the same as that by the latter on the former? If so, the game is one of zero-sum, and the existence of peer effect has no policy value. In contrast, if the effect is nonlinear, it would be possible to optimize the accumulation of human capital through policy intervention. Second, existing natural experiments based on randomly roommate assignment mostly use official data rather than survey data. Therefore, the information of target students' attitudes and behaviors are absent. The collection of such data would be very helpful in deepening this research. Finally, comparative studies of multiple institutional contexts are severely lacking. Existing studies all focus on one school, but different schools vary considerably in terms of institution and students, which can also influence our evaluation on the effect of peer social capital.

Abbreviation

CEE: College Entrance Exam; CPC: Communist Party of China 
Authors' contributions

This study is an independent composition. The author designed the research and read and approved the final manuscript.

\section{Funding}

This study is funded by the Project of National Social Science Fund (Project No.: 17CSH064).

\section{Availability of data and materials}

The ownership of the official data used in this study belonged to C University, and due to the privacy of students' personal information, the data cannot be shared to readers temporarily.

\section{Competing interests}

The author declares that he has no competing interests.

Received: 16 August 2019 Accepted: 20 January 2020

Published online: 13 February 2020

\section{References}

Austin, Peter C. 2011. An Introduction to Propensity Score Methods for Reducing the Effects of Confounding in Observational Studies. Multivariate Behavioral Research 46 (3): 399-424.

Becker, Gary S. 1962. Investment in Human Capital: A Theoretical Analysis. The Journal of Political Economy 70 (5): 9-49.

Bian, Yanjie. 1997. Bringing Strong Ties Back in: Indirect Ties, Network Bridges, and Job Searches in China. American Sociological Review 62 (3): 366-385.

Bian, Yanjie, Xianbi Huang, and Lei Zhang. 2015. Information and Favoritism: The Network Effect on Wage Income in China. Social Networks 40: 129-138.

Blau, Peter M., and Otis Dudley Duncan. 1967. The American Occupational Structure. New York: Wiley.

Brand, Jennie E., and Xie Yu. 2010. Who Benefits Most from College? Evidence for Negative Selection in Heterogeneous Economic Returns to Higher Education. American Sociological Review 75 (2): 273-302.

Brunello, G., M. De Paola, and V. Scoppa. 2010. Peer Effects In Higher Education: Does the Field of Study Matter? Economic Inquiry 48 (3): 621-634.

Buchmann, Claudia, and Ben Dalton. 2002. Interpersonal Influences and Educational Aspirations in 12 Countries. Sociology of Education 75 (2): 99-122.

Burt, R.S. 2001. Structural Holes versus Network Closure as Social Capital. In Social capital: theory and research, ed. N. Lin, K. Cook, and R.S. Burt. New York: Aldine De Gruyter.

Burt, R.S., and K. Burzynska. 2017. Chinese Entrepreneurs, Social Networks, and Guanxi. Management and Organization Review 13 (2): $221-260$.

Carbonaro, William J. 1999. Opening the Debate on Closure and Schooling Outcomes: Comment on Morgan and Sørensen. American Sociological Review 64 (5): 682-686.

Chen, Y.S., and X. Fan. 2011. Estimation of Labor Market Effect of Social Capital: Review of Literature on Endogenous Problems and Research Strategy. Sociological Studies 1: 167-195.

Chen, Y.S., and B. Volker. 2016. Social Capital and Homophily both Matter for Labor Market Outcomes: Evidence from Replication and Extension. Social Networks 45: 18-31.

Cheng, Cheng. 2012. College Students' Social Network, Knowledge Level and Status Attainment. Youth Studies 2: 22-34

Cheng, Cheng. 2015. Peer effects in college students' consumption. Youth Studies 2: 1-9.

Cheng, Cheng, and Yanjie Bian. 2014. Social Capital and the Reproduction of Inequaltiy: The Case of Income Differential between Rural Migrants and Urban Workers. Society 4: 67-90.

Cheng, Cheng, Yixuan Wang, and Yanjie Bian. 2015. Gender-Eraning Differentials in China's Urban Labor Market: A Social Capital Perspective. Population Research 2: 3-16

Christakis, Nicholas A., and James H. Fowler. 2013. Social Contagion Theory: Examining Dynamic Social Networks and Human Behavior. Statistics in Medicine 32 (4): 556-577.

Coleman, James. 1961. The Adolescent Society. New York: Free Press of Glencoe.

Coleman, James. 1988. Social Capital in the Creation of Human Capital. American Journal of Sociology 94: S95-S120.

Davies, Mark, and Denise B. Kandel. 1981. Parental and Peerlnfluences on Adolescents' Educational Plans. American Journal of Sociology 87 (2): 363-387.

DiMaggio, P., and F. Garip. 2012. Network Effects and Social Inequality. Annual Review of Sociology 38: 1887-1933.

Duncan, Otis Dudley, Archibald O. Haller, and Alejandro Portes. 1968. Peer Influences on Aspirations: A Reinterpretation. American Journal of Sociology 74 (2): 119-137.

Foster, G. 2006. It's not Your Peers, and It's not Your Friends. Journal of Public Economics 90 (8-9): 1455-1475.

Galiani, S., and E. Schargrodsky. 2010. Property Rights for the Poor: Effects of Land Titling. Journal of Public Economics 94 (910): $700-729$.

Giordano, Peggy C. 2003. Relationships in Adolescence. Annual Review of Sociology 29: 257-281.

Griffith, A.L., and K.N. Rask. 2014. Peer Effects in Higher Education: A Look at Heterogeneous Impacts. Economics of Education Review 39: 65-77.

Guo, G., Y. Li, H.Y. Wang, T.J. Cai, and G.J. Duncan. 2015. Peer Influence, Genetic Propensity, and Binge Drinking. American Journal of Sociology 121 (3): 914-954.

Haller, Archibald O., and Charles E. Butterworth. 1960. Peer Influences on Levels of Occupational and Educational Aspiration. Social Forces 38 (4): 289-295.

Hasan, S., and S. Bagde. 2013. The Mechanics of Social Capital and Academic Performance in an Indian College. American Sociological Review 78 (6): 1009-1032.

Haynie, D.L., and D.W. Osgood. 2005. Reconsidering Peers and Delinquency: How do Peers Matter? Social Forces 84 (2): 1109 1130. 
Kremer, M., and D. Levy. 2008. Peer Effects and Alcohol Use among College Students. Journal of Economic Perspectives 22 (3): 189-206.

Liang, Yucheng. 2010. Is Social Capital and Social Networks Useless? Sociological Studies 5: 50-82.

Lin, Nan. 1999. Social Networks and Status Attainment. Annual Review of Sociology 25: 467-487.

Lu, Yao, Danching Ruan, and Gina Lai. 2013. Social Capital and Economic Integration of Migrants in Urban China. Social Networks 35 (3): 357-369.

Manski, C.F. 1993. Identification of Endogenous Social Effects: the Reflection Problem. Review of Economic Studies 60 (3): $531-$ 542 .

McDill, Edward L., and James Coleman. 1965. Family and Peer Influences in College Plans of High School Students. Sociology of Education 38 (2): 112-126.

McPherson, M., L. Smith-Lovin, and J.M. Cook. 2001. Birds of a Feather: Homophily in Social Networks. Annual Review of Sociology 27: 415-444.

Morgan, S.L., and A.B. Sorensen. 1999. Parental Networks, Social Closure, and Mathematics Learning. American Sociological Review 64 (5): 661-681.

Mouw, T. 2006. Estimating the Causal Effect of Social Capital: A Review of Recent Research. Annual Review of Sociology 32: 79-102.

Petticrew, Mark, Steven Cummins, Catherine Ferrell, Anne Findlay, Cassie Higgins, Caroline Hoy, Adrian Kearns, and Leigh Sparks. 2005. Natural Experiments: an Underused Tool for Public Health? Public Health 119 (9): 751-757.

Portes, Alejandro. 1998. Social Capital: Its Origins and Applications in Modern Sociology. Annual Review of Sociology 24: 1-24.

Ream, Robert K., and Russell W. Rumberger. 2008. Student Engagement, Peer Social Capital, and School Dropout among Mexican American and Non-Latino White Students. Sociology of Education 81 (2): 109-139.

Rich, Harris Judith. 2009. The Nurture Assumption: Why Children Turn Out the Way They Do. New York: Free Press.

Sacerdote, B. 2001. Peer Effects with Random Assignment: Results for Dartmouth Roommates. Quarterly Journal of Economics $116(2): 681-704$

Sacerdote, B. 2011. Peer Effects in Education: How Might They Work, How Big Are They and How Much Do We Know Thus Far? PP 249-277, In Erik Hanushek, Stephen Machin, and Ludger Woessmann (eds.) Handbook of the Economics of Education. Amsterdam: North Holland.

Sacerdote, B. 2013. Social Networks and the Identification of Peer Effects Comment. Journal of Business \& Economic Statistics 31 (3): 275.

Sacerdote, B. 2014. Experimental and Quasi-Experimental Analysis of Peer Effects: Two Steps Forward? Annual Review of Economics 6 (1): 253-272.

Schultz, Theodore W. 1961. Investment in Human Capital. American Economic Review 51 (1): 1-17.

Sewell, William H., Archibald O. Haller, and Alejandro Portes. 1969. The Educational and Early Occupational Attainment Process. American Sociological Review 34 (1): 82-92

Smith, Adam. 2010/1759. The Theory of Moral Sentiments. Penguin, 96-98.

Smith, K.P., and N.A. Christakis. 2008. Social Networks and Health. Annual Review of Sociology 34: 405-429.

Spenner, Kenneth I., and David L. Featherman. 1978. Achievement Ambitions. Annual Review of Sociology 4: 373-420.

Stinebrickner, R., and T.R. Stinebrickner. 2006. What Can be Learned about Peer Effects Using College Roommates? Journal of Public Economics 90 (8-9): 1435-1454.

Dunning, Thad. 2012. Natural Experiments in the Social Sciences: A Design-Based Approach. New York: Cambridge University Press.

Zhao, Yandong, and Yanbi Hong. 2012. Social Capital in Educational Attainment: The Perspectives of Network Resource and Social Closure. Sociological Studies 5: 47-69.

Zimmerman, D.J. 2003. Peer Effects in Academic Outcomes: Evidence from a Natural Experiment. Review of Economics and Statistics 85 (1): 9-23.

\section{Publisher's Note}

Springer Nature remains neutral with regard to jurisdictional claims in published maps and institutional affiliations.

\section{Submit your manuscript to a SpringerOpen ${ }^{\circ}$ journal and benefit from:}

- Convenient online submission

- Rigorous peer review

- Open access: articles freely available online

High visibility within the field

- Retaining the copyright to your article

Submit your next manuscript at $\boldsymbol{\nabla}$ springeropen.com 